\title{
Self-generated thoughts and depression: from daydreaming to depressive symptoms
}

\section{Igor Marchetti *, Eowyn Van de Putte and Ernst H. W. Koster}

Department of Experimental Clinical and Health Psychology, Ghent University, Ghent, Belgium

\section{Edited by:}

Leonhard Schilbach, University Hospital Cologne, Germany

Reviewed by:

James A. Coan, University of Virginia, USA

Jonathan Smallwood, University of York, UK

\section{*Correspondence:}

Igor Marchetti, Department of

Experimental Clinical and Health

Psychology, Ghent University, Henri

Dunantlaan 2, B-9000 Ghent,

Belgium

e-mail: igor.marchetti@ugent.be
Human minds often engage in thoughts and feelings that are self-generated rather than stimulus-dependent, such as daydreaming. Recent research suggests that under certain circumstances, daydreaming is associated with adverse effects on cognition and affect. Based on recent literature about the influence of resting mind in relation to rumination and depression, this questionnaire study investigated mechanisms linking daydreaming to depressive symptoms. Specifically, an indirect effect model was tested in which daydreaming influences depressive symptoms through enhancing self-focus and ruminative thought. Results were in line with the hypothesis and several alternative pathways were ruled out. The results provide initial supportive evidence that daydreaming can influence depressive symptoms through influences on self-focus and rumination. Further research should use prospective or experimental designs to further validate and strengthen these conclusions.

Keywords: self-generated thought, daydreaming, mindwandering, self-focus, rumination, depressive symptoms, mindfulness, Default Mode Network
All the daydreams are ego-centred.[...]

Each of the daydreams is like a little play, whose hero is the dreamer himself

G. H. Green (1923, pp. 27-28)

\section{INTRODUCTION}

It often happens that one's mind drifts away from what one is doing or that one's attention fluctuates inward during rest. For instance, in everyday life it is a common experience, while reading a book, not to be able to recall the last page, or during a long train ride, to spend a large part of time being unaware of the other passengers. In other words, there is ample evidence that human mind often focuses on mental contents arising independently from the direct environment or the task at hand (Smallwood and Schooler, 2006; Smallwood, 2013). Consequently, this specific process has been defined "self-generated thought" (SGT; Smallwood, 2013).

Throughout decades, SGT has been operationalized in different ways (Callard et al., 2013), by focusing either on its independence from the ongoing task (i.e., stimulus-independent thought; Mason et al., 2007) or the internal rather than external source of information (i.e., spontaneous thought; Christoff et al., 2011). We here choose to operationalize SGT as "daydreaming" (Klinger, 2013), which is a comprehensive phenomenon that, beyond (i) being based on SGT, gathers all the mental states sharing crucial characteristics, such as (ii) the same neurobiological substrate (Stawarczyk et al., 2011), and (iii) similar subjective content (Smallwood and Schooler, 2006). By doing so, we have multiple advantages, such as being allowed to capitalize on previous literature (Klinger, 1971, 1990, 2009, 2013) and the related instruments of measurement (Singer and Antrobus, 1970, 1972; Giambra, 1980).
Daydreaming is conceived as "nonworking thought that is either spontaneous or fanciful" (Klinger, 2009, p. 226) and it is considered the default mode of the mind (Klinger, 1971; Mason et al., 2007). This definition includes SGT unrelated to the task at hand, also known as mindwandering (Smallwood and Schooler, 2006), as well as instances when the mind wanders toward fanciful topics during rest (Klinger, 1971). The value of this definition has been confirmed recently by studies showing that daydreaming is enrooted in a specific large-scale neurobiological network (Mason et al., 2007; Christoff et al., 2009) known as the Default Mode Network (DMN). The DMN is a neural network that is highly active during rest and less active, if not deactivated, during intense task engagement (Raichle et al., 2001). This network has been associated with a list of mental functions that are characterized by an internal focus, among which daydreaming seems to play a major role. Mason et al. (2007) have shown that when participants' minds drifted away from a well-practiced task, high levels of DMN activation were observed. Interestingly, the activation levels of DMN hub areas were correlated with a well-established self-report measure of daydreaming, the Daydreaming Frequency Scale (DDFS, Singer and Antrobus, 1970).

As mental baseline, daydreaming is a frequent phenomenon. Estimates suggest that we spend $30-50 \%$ of our mental activity during waking hours in thoughts that are neither related to what we are doing at that moment nor to the immediate surrounding environment (Klinger and Cox, 1987/88; Killingsworth and Gilbert, 2010; Franklin et al., 2013). In light of this ubiquity, it would be hard to believe that SGT does not serve specific functions, be it adaptive or maladaptive (Klinger, 1996, 2013). Although rarely studied until recently, the benefits of SGT are increasingly being reported in regard to different domains (Mooneyham and Schooler, 2013), for instance creative thinking (Baird et al., 2012), autobiographical planning (Smallwood et al., 
2011), and delaying gratification (Smallwood et al., 2013). Nevertheless, several costs of SGT have been documented as well. Daydreaming, and specifically the mindwandering subtype, has been shown to detrimentally impact on reading comprehension (Franklin et al., 2011), sustained attention (Smallwood et al., 2004), and working memory (McVay and Kane, 2012).

In line with these findings, daydreaming, especially if characterized by negative cognitions, has been associated with symptoms of psychopathology, such as depression, schizophrenia, anxiety, and dissociation (Klinger et al., 2009; Andrews-Hanna et al., in press). What also confirms the potentially toxic role of daydreaming is that its neurobiological substrate has been consistently found to be affected in major psychopathology, such as schizophrenia and depression (Whitfield-Gabrieli and Ford, 2012).

Depression is an important context within which to investigate the clinical impact of daydreaming, as this disorder involves spending much time in inactivity, after which higher levels of depressed mood and lower levels of mastery and pleasure are shown (Martinsen, 2008). In line with this, many studies have indeed reported a clear and direct relation between daydreaming and depressive symptoms (Golding and Singer, 1983; Stawarczyk et al., 2011; Epel et al., 2013). For instance, Giambra and Traynor (1978) have shown that the frequency of and the tendency to be absorbed by daydreaming, especially if negatively valenced, correlated with three different measures of depression. Recently, Meyer et al. (2011) confirmed this finding, reporting that the tendency to engage in daydreaming was predicted by both the severity of current depressive symptoms and the likelihood of former depressive episodes. Furthermore, in a laboratory setting, individuals with subclinical levels of depression exhibited more accessible periods of mindwandering while encoding verbal material, greater attentional control failures, and higher physiological response than euthymic individuals (Smallwood et al., 2007).

Nevertheless, other studies did not support this link between depression and daydreaming in the same clear way, but proposed a more specific relation. Deng et al. (2012) reported that levels of depressive symptoms correlated only with the rate of episodes of mindwandering that occurred without the participant's awareness of being off task (e.g., l "zoned out"), but not with those episodes of which a participant was aware (e.g., "tuned out"). Moreover, Marchetti et al. (2012b) showed that individuals' levels of depressive symptoms were not correlated with mindwandering, but the former moderated the latter in predicting the accessibility of negative thinking. In keeping with this result, Smallwood et al. (2004/05) also reported that the rate of being off task correlated with individuals' mean scores of depression, but only in high ruminators and not in low ruminators.

This inconsistency in findings highlights the need to clarify the mechanism(s) through which daydreaming can lead to negative outcomes. Shedding light on the underlying process could indeed help understand what conditions increase the likelihood of negative outcomes related to daydreaming. Recently, Marchetti et al. (under review) proposed a comprehensive model that could explain the depressogenic role of daydreaming via contribution of multiple cognitive risk factors, such as rumination. In keeping with this, Marchetti et al. (2013) demonstrated in a laboratory setting that higher levels of internal focus during resting state predicted increased levels of state rumination that, in turn, explained a temporary worsening in mood. This model specifically held in individuals at-risk for depression. The authors speculated that being internally focused during rest could facilitate the emergence of self-related material that is the ideal condition for rumination to occur (Nolen-Hoeksema et al., 2008). Rumination, in turn, has been consistently found to enhance depressive symptoms (Aldao et al., 2010). Literature consistently reports that during SGT external information is processed to a lesser extent (Smilek et al., 2010; Barron et al., 2011), and the train of thoughts is largely insulated (Smallwood et al., 2012). Such reduced processing of external distractions could augment repetitive thinking (Nolen-Hoeksema et al., 2008).

In the current study, we aimed to test the indirect effect hypothesis that: (a) during daydreaming, self-related material would be significantly present in individuals' awareness; (b) being self-focused during SGT would spur ruminative processing of the emerged material; (c) a rigid and judgmental evaluation of internal material would lead to depressive symptoms. Given the inconsistent findings mentioned above, we did not make any $a$ priori hypothesis about a direct association between daydreaming and depressive symptoms. Our study contributes to this research field in different ways. Importantly, by testing this model, we can further specify the mechanisms through which daydreaming is toxic and detrimental for mental health. Moreover, by relying on self-report questionnaires, our study may complement previous research that, although methodologically rigorous, suffers from suboptimal ecological validity, such as fMRI or specific laboratory contexts.

Therefore, we administered several trait questionnaires to measure individual levels of daydreaming (vs. mindfulness), selffocus, rumination, and depressive symptoms. Importantly, the scale we adopted as a measure for spontaneous cognitions, the DDFS, was previously used in both neurobiological and behavioral studies that confirmed its solid relation with the DMN (Mason et al., 2007) and rest-related phenomena, such as mindwandering (Mrazek et al., 2012; Stawarczyk et al., 2012). Moreover, in order to evaluate the specific role of daydreaming in predicting depressive outcomes, we controlled for dispositional level of mindfulness. Mindfulness has been defined in different ways, but here we focused on the perspective that defines mindfulness as sustained non-distraction from here and now (Brown and Ryan, 2003). By partialling it out, we could establish the specific role of daydreaming above and beyond the potential confound of mindfulness.

\section{MATERIALS AND METHODS PARTICIPANTS}

We recruited 117 native Dutch-speaking students at Ghent University (mean age $21.51 \pm 3.04$, range: 20-46, F: 116 and M: $1^{1}$ ). This study was approved by the Ethical Committee of the faculty of Psychology and Education of Ghent University.

\footnotetext{
${ }^{1}$ All the analyses reported in this study did not substantially change after excluding the only male participant.
} 


\section{DESIGN}

The questionnaires were completed in a group setting. The order of the questionnaires was counterbalanced ${ }^{2}$.

\section{MATERIALS}

Daydreaming Frequency Scale (DDFS; Singer and Antrobus, 1970)

The DDFS is one of the scales forming the Imaginal Processes Inventory. It consists of 12 items used to assess the frequency of daydreaming. Respondents rate each item on a 5-point Likert scale. Previous studies have reported good to excellent psychometric properties (Singer and Antrobus, 1970). For instance, both the English and the French version have been found to be unifactorial with substantial loading of each item (Singer and Antrobus, 1970; Stawarczyk et al., 2012). The instrument also has excellent 6-8 years test-retest reliability $(r=0.76)$ and internal consistency (Cronbach's $\alpha=0.91$ ) (Giambra, 1980). In the current study, the original 12 items were translated from English to Dutch independently by two native Dutch speakers with excellent knowledge of academic English. Importantly, one of the translators was one of the authors of this study (Ernst H. W. Koster), whereas the other translator was not involved in this research. Discrepancies between these two versions were discussed until a satisfactory version was found. In this study, excellent internal consistency was observed (Cronbach's $\alpha=0.91$ ).

\section{Self-Reflection and Insight Scale (SRIS; Grant et al., 2002)}

The SRIS is a 20-item self-report questionnaire, consisting of two independent subscales, the Self-Reflection subscale (SRIS-SR) and the Insight subscale (SRIS-IN). The SRIS-SR scale includes 12 items and measures the tendency to self-focus, that is to think about one's own thoughts, actions, and feelings and evaluate them. The SRIS-IN consists of 8 items that assess clarity of experience and self-knowledge. Each item is measured on a 6-point Likert scale ranging from 1 (strongly disagree) to 6 (strongly agree). The SRIS has high internal consistency and internal validity (Grant et al., 2002; Roberts and Stark, 2008). The Dutch version of the questionnaire had good psychometric properties (Sauter et al., 2010) and in the current sample, the SRIS-SR and SRIS-IN showed excellent internal consistency (Cronbach's $\alpha=0.94$ for SRIS-SR; $\alpha=0.82$ for SRIS-IN).

\section{Ruminative Responses Scale (RRS; Treynor et al., 2003)}

The RRS is a 22-item self-report questionnaire that measures habitual tendency to ruminate and consists of items that describe responses to depressed mood that are focused on the self, symptoms, or consequences of this mood. Participants rate to what extent they usually engage in such responding using a 4-point Likert scale ranging from 1 (almost never) to 4 (almost always). Total RRS scores and subscale scores for reflection and depressive brooding were also calculated. The RRS has shown high reliability and validity and has good psychometric properties (Treynor et al., 2003). The Dutch version of the instrument also has good

\footnotetext{
${ }^{2}$ Another trait questionnaire of self-focus, the Private Self-Consciousness Scale (PrSCS, Fenigstein et al., 1975), was also administered. The analysis did not change substantially when the PrSCS was used. For sake of brevity, these results were not reported.
}

reliability and satisfactory validity (Raes et al., 2003). Internal consistency of the RRS and its subscales in the current study was good (Cronbach's $\alpha=0.93$ for the total score; $\alpha=0.77$ for the brooding subscale; $\alpha=0.74$ for the reflection subscale).

\section{Beck Depression Inventory 2nd Edition (BDI-Il; Beck et al., 1996)}

The BDI-II is a 21-item self-report questionnaire, which assesses the severity of affective, somatic and cognitive symptoms of depressive phenomenology. Individuals rate each symptom on a scale ranging from 0 to 3 . The Dutch version of the BDI-II we used has acceptable reliability and validity (Van der Does, 2002). In our study, the BDI-II had excellent internal consistency (Cronbach's $\alpha=0.85$ ).

Mindful Attention Awareness Scale (MAAS; Brown and Ryan, 2003) The MAAS is a self-report 15-item questionnaire. Participants are required to rate each item on a 6-point Likert type scale, ranging from 1 (almost always) to 6 (almost never). The MAAS evaluates mindfulness as attention and awareness toward emotions, thoughts, sensations, and situations. Higher scores on the MAAS reflect higher levels of dispositional mindfulness. The Dutch translation of the MAAS was made available by the authors of the original instrument and in our study we found excellent internal consistency (Cronbach's $\alpha=0.81$ ).

\section{DATA-ANALYTIC STRATEGY}

We first investigated the psychometric properties of the Dutch version of the DDFS. Initially, we checked the single item features and internal consistency through item analysis and Cronbach's alpha respectively. We then carried out an Exploratory Factor Analysis (EFA) on the Pearson's correlation matrix by means of Principal Axis Factoring (PAF) with oblique rotation (Oblimin) to highlight the factorial structure of the instrument. According to established guidelines (Zwick and Velicer, 1986), we retained the number of factors suggested by the scree plot (Cattell, 1966; see Figure 1), the Parallel Analysis (PA; Horn, 1965; see Figure 1), and the Minimum Average Partial Correlation statistic (MAP; Velicer, 1976). The analyses were carried out with IBM SPSS 19 and FACTOR 8.02 (Lorenzo-Seva and Ferrando, 2006).

We then checked the descriptive statistics and Pearson's correlations among all the variables measured in this study. Spearman's rank correlation coefficient was computed when necessary. Data were transformed to either obtain normally distributed variables or correct for outliers $(z$ point $>3)$. No participants were excluded.

According to our hypothesis (see Figure 2A), we first tested whether trait daydreaming could explain higher levels of selffocus (path $a_{1}$ ), which in turn was expected to account for higher levels of brooding (path $a_{3}$ ). The final output of this serial mediation model was individual levels of depressive symptoms (path $b_{2}$ ). We did not have a specific hypothesis regarding either the total (path $c$ ) or the direct (path $c^{\prime}$ ) effect of daydreaming with depressive symptoms. According to Mathieu and Mathieu and Taylor's (2006) guidelines, if the indirect effect was found significant, we could refer to this as an indirect effect model only if both the total and direct effect were null. If one or both of these two latter effects were found significant, we should speak of either 


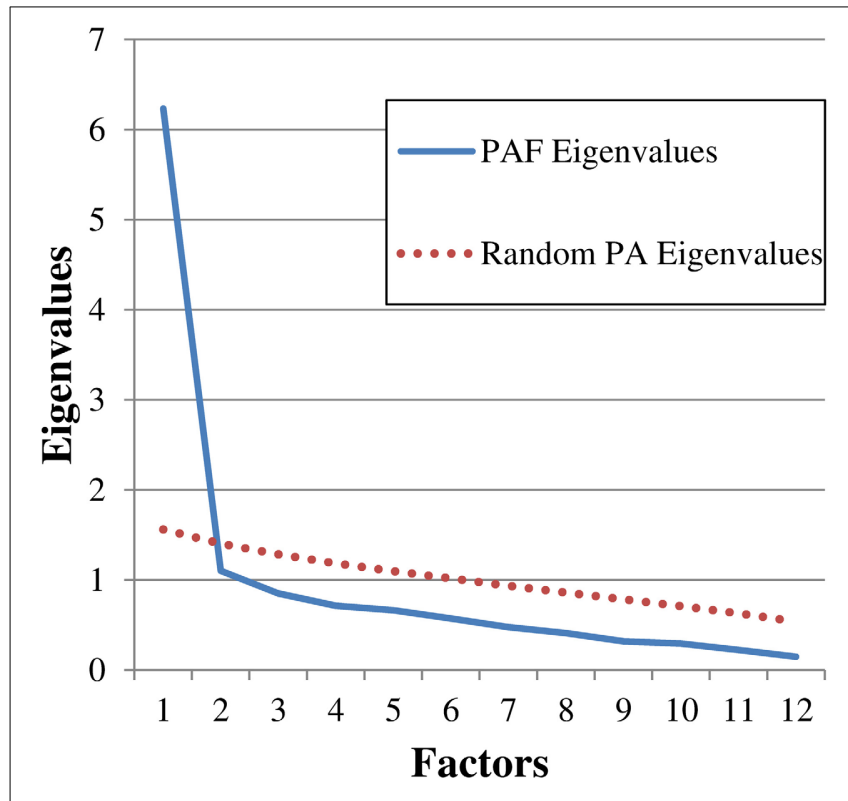

FIGURE 1 | Scree plot showing the eigenvalues derived from both the Principal Axis Factoring (PAF) and the Parallel Analysis (PA). PAF eigenvalues: $6.23,1.10,0.85,0.71,0.66,0.57,0.47,0.41,0.32,0.29,0.22$, 0.15 . Random PA eigenvalues (12 variables, $n=117,1000$ replications): $1.56,1.40,1.28,1.18,1.09,1.01,0.93,0.85,0.78,0.70,0.62,0.53$.

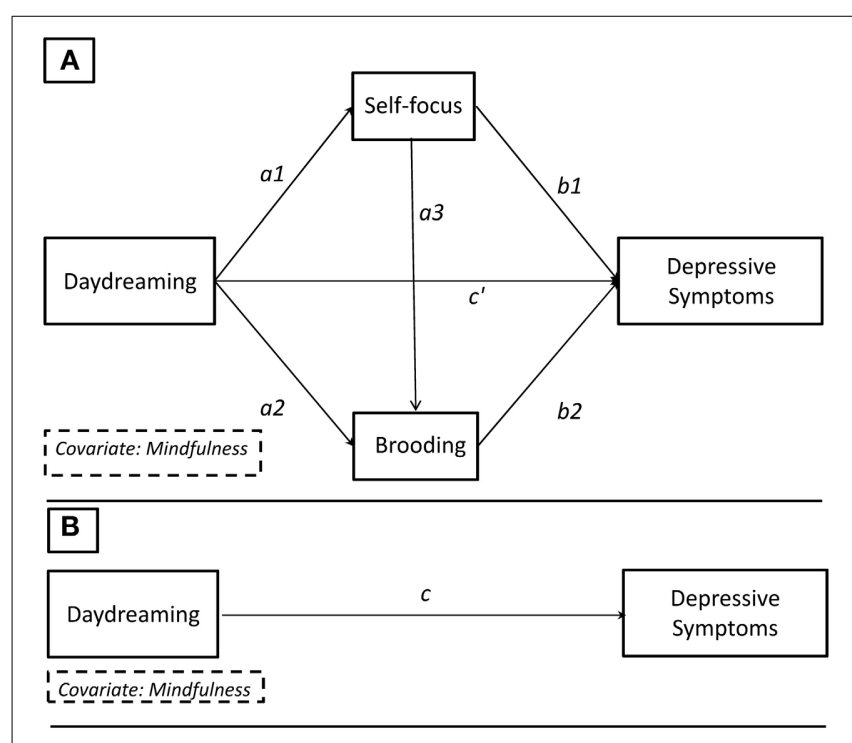

FIGURE 2 | Theoretical path diagram showing the multiple serial mediation model. (B) Path c: total effect. (A) Path $c^{\prime}$ : direct effect. Path $a_{1} a_{3} b_{2}$ : specific indirect effect of interest.

full or partial mediation model (Preacher and Hayes, 2008). Given that daydreaming and mindfulness are thought to represent negatively related constructs, with the former capturing the tendency of the mind to drift away and the latter the tendency to be aware of the present moment (Deng et al., 2012; Mrazek et al., 2012), we always included the mindfulness as a covariate in all the models in which daydreaming was the focal predictor in order to establish its contribution above and beyond mindfulness ${ }^{3}$.

In our study, the total effect (path $c$ ) was computed as the regression coefficients of daydreaming and mindfulness predicting depressive symptoms, while none of the intervening variables were included in the model. According to the mediation theory (Hayes, 2013), it was possible to decompose the total effect in two main parts, that is the direct effect (path $c^{\prime}$ with depressive symptoms being regressed on daydreaming, self-focus, brooding, and mindfulness) and the total indirect effect. The latter could, in turn, be decomposed into three specific indirect effects where daydreaming influenced depressive symptoms via: (i) self-focus (path $a_{1} b_{1}$ ); (ii) brooding (path $a_{2} b_{2}$ ); self-focus and brooding serially (path $a_{1} a_{3} b_{2}$ ). By definition, the sum of the direct effect and the total indirect effect equates to the total effect of daydreaming on depressive symptoms.

To test the significance of both the total and specific indirect effects, we adopted the bootstrapping approach (Preacher and Hayes, 2008). Compared with the causal steps approach (Baron and Kenny, 1986) or the Sobel test (Sobel, 1982), bootstrapping is considered the most powerful approach, to be free from unrealistic assumptions (i.e., normal distribution of the indirect effect), and to have better control on Type I error (Hayes, 2009, 2013). In line with Preacher and Hayes' recommendations (2008), to test the significance of the indirect effects, we estimated 10,000 bootstrap bias-corrected $95 \%$ confidence intervals (CIs), and if they did not contain zero they were considered significant. The core hypothesis we tested was the model whereby daydreaming influences depressive symptoms via self-focus and brooding serially (path $a_{1} a_{3} b_{2}$ ). However, in order to rule out alternative paths belonging to the same statistical model, we also estimated the other specific indirect effects (Hayes, 2013), where the intervening variables were introduced one at a time, that is either path $a_{1} b_{1}$ or path $a_{2} b_{2}$. In order to clarify the direction of the indirect effects, we also estimated each single path (e.g., $a_{1}, a_{2}, a_{3}, b_{1}$, and $b_{2}$ ) using an ordinary least squares regression. Finally, in adherence with Mathieu and Taylor's guidelines (2006), we tested both the direct (path $c^{\prime}$ ) and the total effect (path $c$ ).

Given that our study was purely cross-sectional, we tried to rule out two other serial indirect effects that would work against our main hypothesis. In the first alternative model, we substituted brooding with the reflection subscale of the RRS as the second intervening variable. Although both reflection and brooding are essentially forms of self-focus and self-referential thinking, reflection is known not to lead to negative outcomes, such as depressive symptoms (Nolen-Hoeksema et al., 2008). We thus expected the model, in which daydreaming influences depressive symptoms via self-focus and reflection, not to be significant. The second alternative model proposes that self-focus leads to increased daydreaming, which in turn could explain depressive brooding and depressive symptoms. Self-focus induction indeed has been reported to influence the tendency of the mind to drift away from external reality toward the inner mental world (Smallwood et al., 2011). However, it is difficult to explain how

\footnotetext{
${ }^{3}$ All the analyses reported did not substantially change after excluding MAAS as covariate.
} 
and why daydreaming, after being purged of its self-related component, could lead to rumination. Therefore, we anticipated this model would not be significant either.

All the analyses were carried out with IBM SPSS 19 and the macro PROCESS 2.03 (Hayes, 2013).

\section{RESULTS}

\section{PRELIMINARY ANALYSIS: PSYCHOMETRIC PROPERTIES OF THE DAYDREAMING FREQUENCY SCALE (DDFS)}

We evaluated the psychometric properties of the Dutch version of the DDFS on the total sample. The inter-item correlation matrix showed that all the DDFS items were positively correlated, mean $r=0.47$ (range: $0.17-0.84$ ), as well as the mean-corrected itemtotal correlation was $r=0.65$ (range: $0.51-0.79$ ). Cronbach's alpha revealed excellent internal consistency $(\alpha=0.91)$, which was not improved by item deletion. Before conducting the PAF on the 12 items, we checked the assumptions through the KaiserMeyer-Olkin criterion $(\mathrm{KMO}=0.91)$ and the Bartlett's test of sphericity $\left[\chi_{(66)}^{2}=773.28, p<0.001\right]$, which highlighted sufficient sample size and data quality (Gorsuch, 1983).

The scree plot inspection (see Figure 1), the Parallel Analysis (PA; Figure 1), and the Minimum Average Partial Correlation test (MAP, average partial correlation $=0.331$ ) strongly supported the one-factor solution, which explained $51.93 \%$ of the variance in the unrotated matrix. All the items loaded on the factor substantively, that is $=0.54$ (range: $0.54-0.84$ ). According to Stevens (2002), for sample sizes of 100 subjects, only loadings greater than. 51 should be interpreted.

In sum, we confirmed that the Dutch version of the DDFS is unifactorial and all the items significantly represent the underlying factor. We thus adopted the sum of the 12 DDFS items as our main variable in this study.

\section{DESCRIPTIVE STATISTICS AND CORRELATIONAL ANALYSIS}

Means, standard deviations, Cronbach's alphas and correlations between the questionnaire measures are reported in Table 1.

In line with our hypothesis, daydreaming frequency was positively correlated with self-focus measured with the selfreflection scale (SRIS-SF). Daydreaming was also correlated with rumination, and specifically with depressive brooding, but not with reflection. In line with a previous study and current theoretical perspectives (Marchetti et al., 2013, under review), daydreaming seems to be a phenomenon during which evaluative and judgmental self-referential thinking occurs. This was also supported by the negative relationship between the insight scale (SRISIN) and daydreaming. Daydreaming seems not to be beneficial with regard to the clarity of reflection and self-understanding; on the contrary, it may impair these processes. In sum, although daydreaming is focused on the daydreamer's narrative self (e.g., action, feelings, past events, etc.), it is not associated with any immediate beneficial outcome, rather it is the ideal condition for detrimental ruminative self-focus to occur. Moreover, daydreaming was independent from depressive symptoms, whereas it was negatively correlated with being aware at the present moment. It is noteworthy that this modest negative relation between daydreaming and mindfulness has been reported previously in other studies (i.e., $r=-0.237$; Mrazek et al., 2012). Importantly, not only does this result confirm a previous finding (Mrazek et al., 2012), but also it provides information about the divergent validity of the Dutch version of the DDFS.

\section{MEDIATION ANALYSIS}

In accordance with Mathieu and Taylor's guidelines (2006), we first tested the significance of the main indirect effect of interest, namely that daydreaming would explain the levels of depressive symptoms via self-focus and brooding levels serially (path $a_{1} a_{3} b_{2}$; Figure 2). Table 2 shows that this three-step indirect effect was indeed statistically significant (path $a_{1} a_{3} b_{2}=0.0014$; boot $95 \%$ CI LL $=0.0004$, boot $95 \%$ CI UL $=0.0036$ ). Moreover, all the single paths of this effect were in the expected direction (Table 3 ). Indeed, daydreaming positively predicted self-focus (path $a_{1}=$ 0.036 ), which, in turn, positively predicted brooding (path $a_{3}=$ 0.149 ). Finally, brooding positively predicted depressive symptoms (path $b_{2}=0.249$ ). It is noteworthy that the simpler alternative indirect paths were both not significant. The indirect effect whereby daydreaming influences depressive symptoms only via self-focus failed to reach statistical significance (path $a_{1} b_{1}=$ 0.0005 ; boot $95 \%$ CI LL $=-0.0012$, boot $95 \%$ CI UL $=0.0029$ ).

Table 1 | Means, standard deviations, Cronbach's alpha, and Pearson's correlations ( $n=117)$.

\begin{tabular}{|c|c|c|c|c|c|c|c|c|c|c|c|c|c|}
\hline & $M$ & $S D$ & $s K$ & $K$ & Min-max & DDFS & SRIS-SR ${ }^{a}$ & SRIS-IN & RRS $^{\mathbf{a}}$ & Brooding $^{a}$ & Reflection & BDI-II ${ }^{a}$ & MAAS \\
\hline SRIS-SR & 51.39 & 9.91 & -0.70 & 0.00 & $23-68$ & & $(0.94)$ & -0.12 & $0.42 * * *$ & $0.40 * * *$ & $0.55^{s * * *}$ & 0.15 & 0.13 \\
\hline RRS & 39.41 & 10.92 & 1.01 & 1.28 & $22-79$ & & & & (0.93) & $0.88^{* * *}$ & $0.73^{S * * *}$ & $0.36 * * *$ & -0.01 \\
\hline Brooding & 9.48 & 3.04 & 0.84 & 0.73 & 5-19 & & & & & $(0.77)$ & $0.56^{S * * *}$ & $0.38 * * *$ & 0.01 \\
\hline Reflection & 7.98 & 2.6 & 1.14 & 0.96 & $5-16$ & & & & & & $(0.74)$ & $0.13^{s}$ & $0.07^{\mathrm{s}}$ \\
\hline
\end{tabular}

${ }^{*} p<0.05 ;{ }^{* *} p<0.01 ;{ }^{* * *} p<0.001$. The values between parentheses are Cronbach's alphas. SK, skewness; K, kurtosis; DDFS, Daydreaming Frequency Scale;

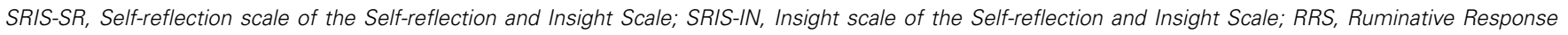
Scale-total score; BDI-II, Beck Depression Inventory 2nd Edition; MAAS, Mindful Attention Awareness Scale.

${ }^{a}$ Data transformed to either obtain normally distributed variables or correct for outliers (z point $>3$ ).

s Spearman's rank correlation coefficient. 
Table 2 | Specific and total indirect effects' unstandardized coefficients, standard error, and $95 \%$ bias-corrected confidence intervals ${ }^{\mathrm{a}}(n=117)$.

\begin{tabular}{lccrc}
\hline Path & $\begin{array}{c}\text { Indirect effect } \\
\text { coefficient }\end{array}$ & $\begin{array}{c}\text { Boot } \\
\text { SE }\end{array}$ & $\begin{array}{c}\text { Boot LL } \\
\text { Cl 95\% }\end{array}$ & $\begin{array}{c}\text { Boot UL } \\
\text { Cl 95\% }\end{array}$ \\
\hline$a_{1} b_{1}$ & 0.0005 & 0.0010 & -0.0012 & 0.0029 \\
$a_{2} b_{2}$ & 0.0019 & 0.0015 & -0.0006 & 0.0057 \\
$a_{1} a_{3} b_{2}$ & 0.0014 & 0.0008 & 0.0004 & 0.0036 \\
Total indirect effect & 0.0037 & 0.0019 & 0.0007 & 0.0082 \\
\hline
\end{tabular}

$a_{1} b_{1}$, Daydreaming $\rightarrow$ Self-focus $\rightarrow$ Depressive symptoms; $a_{2} b_{2}$, Daydreaming $\rightarrow$ Brooding $\rightarrow$ Depressive symptoms; $a_{1} a_{3} b_{2}$, Daydreaming $\rightarrow$ Self-focus $\rightarrow$ Brooding $\rightarrow$ Depressive symptoms.

${ }^{a}$ Mindfulness score (MAAS) was included as covariate.

So did the other alternative path, whereby daydreaming predicts depressive symptoms via brooding levels (path $a_{2} b_{2}=0.0019$; boot $95 \%$ CI LL $=-0.0006$, boot $95 \%$ CI UL $=0.0057$ ). In sum, the three-step indirect effect was the only statistically significant effect, and, despite that it consisted of two intervening variables, it was parsimonious too, in that simpler models did not explain the data satisfactorily (see Figure 3).

We then tested both the total (path $c$ ) and the direct (path $\left.c^{\prime}\right)$ effect using the OLS regression approach. Table 3 shows that both unstandardized coefficients were not significant. We can thus conclude that the hypothesized serial (indirect) effect model was supported and that daydreaming seems to explain depressive symptoms only via the contribution of both self-focus and depressive brooding.

\section{ADDITIONAL ANALYSIS}

We also explored two alternative models that were in contrast to our main hypothesis. We investigated whether the same threestep indirect effect was statistically significant, after removing brooding and including reflection as the second intervening variable. Given the unclear link between reflection and depression (Nolen-Hoeksema et al., 2008), we expected this model would not be significant. In keeping with this, Table 4 shows that this alternative model was in fact not statistically sound (path $a_{1} a_{3} b_{2}=$ 0.0005; boot 95\% CI LL $=-0.0004$, boot 95\% CI UL $=0.0021$ ).

By capitalizing on the literature (Smallwood et al., 2011), we also put forward that self-focus could lead to a habitual tendency to daydream that in turn could explain depressive symptoms via the contribution of brooding. In contrast, our main hypothesis argued that daydreaming would lead to depressive brooding only via the self-referential focus of task-free mental activity. Because of this, we expected that this alternative model would not reach significance. Table 5 shows indeed that self-focus fails to explain depressive symptoms via daydreaming and brooding serially (path $a_{1} a_{3} b_{2}=0.0028$; boot $95 \%$ CI LL $=-0.0003$, boot 95\% CI UL $=0.0113)$.

\section{DISCUSSION}

SGT and mental phenomena that are based on it, such as daydreaming, are increasingly attracting scholars' attention (Klinger, 1971, 1990, 2009, 2013; Smallwood and Schooler, 2006;

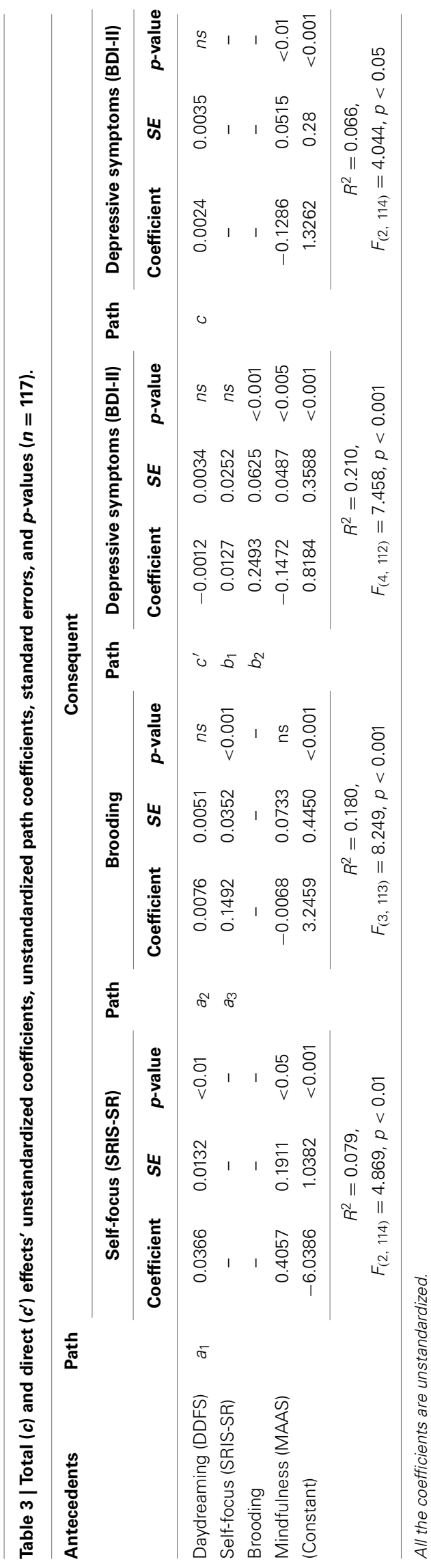




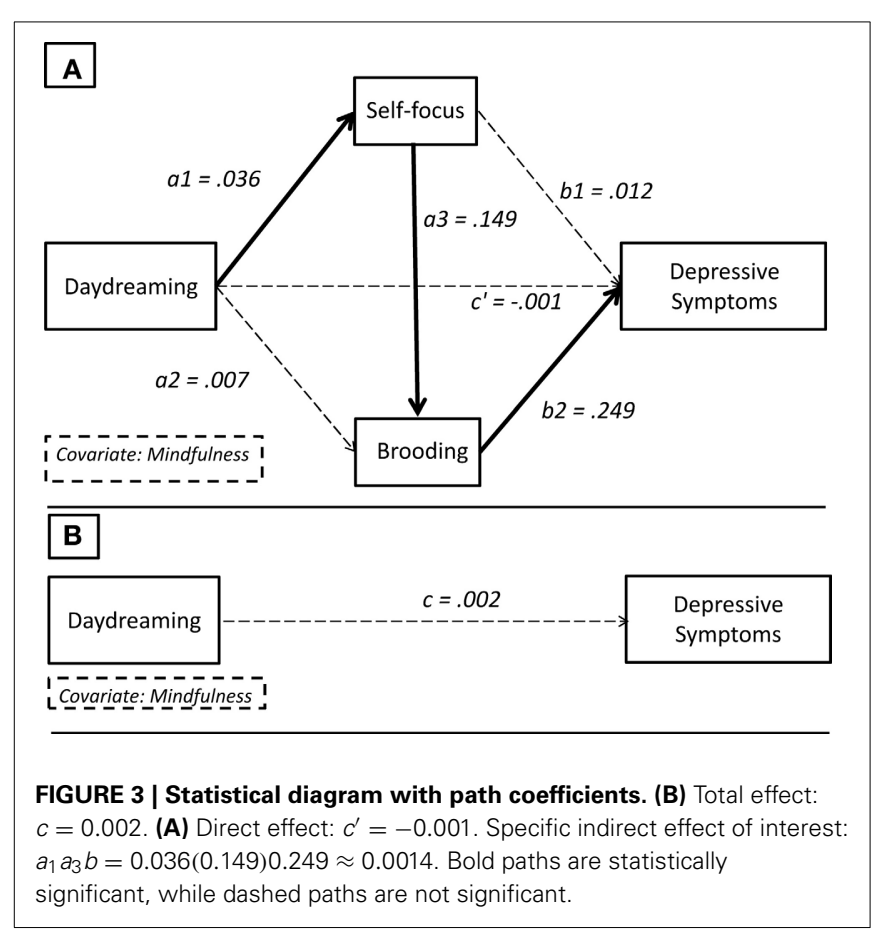

Table 4 | Specific and total indirect effects' unstandardized coefficients, standard errors, and $95 \%$ bias-corrected confidence intervals $^{\mathrm{a}}(n=117)$.

\begin{tabular}{lccrc}
\hline Path & $\begin{array}{c}\text { Indirect effect } \\
\text { coefficient }\end{array}$ & $\begin{array}{c}\text { Boot } \\
\text { SE }\end{array}$ & $\begin{array}{r}\text { Boot LL } \\
\text { Cl 95\% }\end{array}$ & $\begin{array}{c}\text { Boot UL } \\
\text { Cl 95\% }\end{array}$ \\
\hline$a_{1} b_{1}$ & 0.0014 & 0.0013 & -0.0005 & 0.0047 \\
$a_{2} b_{2}$ & 0.0004 & 0.0007 & -0.0003 & 0.0025 \\
$a_{1} a_{3} b_{2}$ & 0.0005 & 0.0006 & -0.0004 & 0.0021 \\
Total indirect effect & 0.0022 & 0.0014 & 0.0001 & 0.0056 \\
\hline
\end{tabular}

$a_{1} b_{1}$, Daydreaming $\rightarrow$ Self-focus $\rightarrow$ Depressive symptoms; $a_{2} b_{2}$, Daydreaming $\rightarrow$ Reflection $\rightarrow$ Depressive symptoms; $a_{1} a_{3} b_{2}$, Daydreaming $\rightarrow$ Self-focus $\rightarrow$ Reflection $\rightarrow$ Depressive symptoms.

a Mindfulness score (MAAS) was included as covariate.

Table 5 | Specific and total indirect effects' unstandardized coefficients, standard errors, and $95 \%$ bias-corrected confidence intervals $(n=117)$.

\begin{tabular}{lccrc}
\hline Path & $\begin{array}{c}\text { Indirect effect } \\
\text { coefficient }\end{array}$ & $\begin{array}{c}\text { Boot } \\
\text { SE }\end{array}$ & $\begin{array}{r}\text { Boot LL } \\
\text { Cl 95\% }\end{array}$ & $\begin{array}{c}\text { Boot UL } \\
\text { Cl 95\% }\end{array}$ \\
\hline$a_{1} b_{1}$ & 0.0025 & 0.0047 & -0.0054 & 0.0139 \\
$a_{2} b_{2}$ & 0.0373 & 0.0141 & 0.0143 & 0.0695 \\
$a_{1} a_{3} b_{2}$ & 0.0028 & 0.0027 & -0.0003 & 0.0113 \\
Total indirect effect & 0.0426 & 0.0151 & 0.0169 & 0.0762 \\
\hline
\end{tabular}

$a_{1} b_{1}$, Self-focus $\rightarrow$ Daydreaming $\rightarrow$ Depressive symptoms; $a_{2} b_{2}$, Self-focus $\rightarrow$ Brooding $\rightarrow$ Depressive symptoms; $a_{1} a_{3} b_{2}$, Self-focus $\rightarrow$ Daydreaming $\rightarrow$ Brooding $\rightarrow$ Depressive symptoms.

Andrews-Hanna et al., in press; Smallwood, 2013) given their ubiquitous impact on mental life. Interestingly, daydreaming has been associated with increased depressive symptoms and negative cognitions (Smallwood et al., 2007; Meyer et al., 2011), although findings are mixed. Here we sought to examine some of the pathways that could potentially explain why and how daydreaming leads to depressive outcomes and, in turn, account for the inconsistency reported in the literature.

In our study, we found that levels of daydreaming and depressive symptoms were statistically independent. However, according to the previous studies and a recent theoretical framework (Marchetti et al., 2013, under review), daydreaming did predict depressive outcomes, but only to the extent to which self-focus and brooding were involved too. In other words, during SGT, our attention tends to be focused on internal scenarios related to our self and self-related goals (Northoff et al., 2006; Klinger, 2009; Diaz et al., 2013). This enhances the chance of ruminating on the (lack of) progress in salient goal-striving (Koster et al., 2011; Klinger, 2013). Unfortunately, such a passive and self-critical evaluation has consistently been reported to be depressogenic (Aldao et al., 2010). It is also noteworthy that, in line with these results, daydreaming was negatively correlated with both mindfulness and the clarity of self-knowledge. That is, people who reported experiencing daydreaming generally did not benefit from being aware of the present moment nor did being self-focused lead them to a better understanding of themselves.

On the one hand, these findings are important because they convey a plausible homological model suggesting possible directional links between crucial constructs in depression, such as daydreaming, self-focus, and brooding. It is also noteworthy that the proposed model could bridge the gap between cognitive and neurobiological science, in that the hypothesis tested in this study is compatible with evidence derived from both research fields. As mental baseline, daydreaming is considered the quintessential outcome of the DMN (Mason et al., 2007), while self-focus has been robustly associated with a specific DMN subnetwork, Cortical Midline Structures (CMS; Northoff et al., 2006). Unsurprisingly, both rumination and clinical depressive status, too, have been linked with higher levels of DMN functional connectivity during resting state (Greicius et al., 2007; Berman et al., 2011; Zhu et al., 2012). Therefore, the model tested in this study holds promise for guiding future neuroimaging studies where trait rumination could be associated with specific dynamics of neural activation of DMN-related brain regions (i.e., Granger causality test; Hamilton et al., 2011).

On the other hand, we believe that our study not only replicated previous findings, but also complements these research lines that may suffer from suboptimal ecological validity. Both fMRI investigations and experimental studies usually require individuals to rest in conditions that are far from those usually experienced. For instance, recent methodological studies highlight the detrimental impact of the scanner background noise on the neural activation of DMN and resting state (Gaab et al., 2008; Hommel et al., 2012; Rondinoni et al., 2013). On the contrary, in our study we did not impose any artificial condition, but we simply investigated stable and long-term dispositions through self-report. By doing so, we may have been able to track specific mechanisms that are more likely to mirror what happens in everyday life, although future experience sampling studies are warranted.

This study has several limitations that we want to acknowledge. First, the research design is totally self-report based and 
methodologically cross-sectional, so that no cause-effect claims can be made. Nevertheless, to partially mitigate this flaw, we ruled out four alternative models. Not only did this support our hypothesis, but it also confirmed the validity of the model, in that no redundant variable was detected. Apparently, both self-focus and maladaptive rumination were necessary components for daydreaming to impact on depressive symptoms. However, in order to be able to further validate the model, behavioral high-risk longitudinal designs are warranted (Alloy et al., 1999). Second, we acquired information only about the frequency of daydreaming and not on its specific content. According to recent perspectives on SGT (Smallwood and Andrews-Hanna, 2013), a factor implicated in the impacting of daydreaming on well-being is its specific content, either positive vs. negative, or past- vs. future-oriented (Klinger et al., 2009; Ruby et al., 2013). Accordingly, future studies should include additional significant variables in order to better specify under which circumstances daydreaming leads to depressive outcomes and, most importantly, when this is not the case. Third, according to our hypothesis aiming at clarifying the role of daydreaming in depression, we did not take into account the possibly positive effects of SGT. For instance, previous research has indeed reported that DDFS is positively correlated with creative thinking (Baird et al., 2012) and neurobiological evidence suggests that SGT could facilitate social cognition (Schilbach et al., 2008, 2012). So, we cannot exclude that possible positive effects due to SGT did go unnoticed in our study.

In sum, the clinical importance of resting state and rest-related phenomena is increasingly being stressed by both researchers and clinicians (Rosner et al., 2004; Whitfield-Gabrieli and Ford, 2012), with different models being proposed (i.e., Marchetti et al., 2012a, under review; Andrews-Hanna et al., in press). In our study, we confirmed a plausible mechanism recently proposed by Marchetti et al. (2013), whereby daydreaming is supposed to impact on depression via contribution of both self-focus and rumination. However, we are not claiming here that daydreaming is negative per se. On the contrary, we have been able to clarify a specific mechanism where self-focus seems to be pivotal (Green, 1923). This also implies that, in individuals with a different style, daydreaming might have different effects, such as in those who tend to be more other-focused than purely self-focused during free thinking (Mar et al., 2012; Marchetti and Koster, 2014).

In conclusion, daydreaming is a very fluid and complex mental activity. Theoretical and empirical efforts are necessary to highlight both the negative and positive consequences of such a pervasive phenomenon that occupies a vast part of our mental life.

\section{ACKNOWLEDGMENTS}

This research was supported by a Grant of the Special Research Fund (BOF) of Ghent University (BOF 10/2JO/061) awarded to Ernst H. W. Koster. The authors wish to thank Dr. L. B. Alloy for her constructive comments on a previous version of this manuscript.

\section{REFERENCES}

Aldao, A., Nolen-Hoeksema, S., and Schweizer, S. (2010). Emotion-regulation strategies across psychopathology: a meta-analytic review. Clin. Psychol. Rev. 30, 217-237. doi: 10.1016/j.cpr.2009.11.004
Alloy, L. B., Abramson, L. Y., Raniere, D., and Dyller, I. M. (1999). "Research methods in adult psychopathology," in Handbook of Research Methods in Clinical Psychology, 2nd Edn., eds P. C. Kendall, J. N. Butcher, and G. N. Holmbeck (New York, NY: Wiley), 466-498.

Andrews-Hanna, J. R., Smallwood, J., and Spreng, R. N. (in press). The default network and self-generated thought: component processes, dynamic control, and clinical relevance. Ann. N.Y. Acad. Sci. doi: 10.1111/nyas. 12360

Baird, B., Smallwood, J., Mrazek, M. D., Kam, J. W., Franklin, M. S., and Schooler, J. W. (2012). Inspired by distraction mind wandering facilitates creative incubation. Psychol. Sci. 23, 1117-1122. doi: 10.1177/0956797612446024

Baron, R. M., and Kenny, D. A. (1986). The moderator mediator variable distinction in social psychological-research-conceptual, strategic, and statistical considerations. J. Pers. Soc. Psychol. 51, 1173-1182. doi: 10.1037/00223514.51.6.1173

Barron, E., Riby, L. M., Greer, J., and Smallwood, J. (2011). Absorbed in thought the effect of mind wandering on the processing of relevant and irrelevant events. Psychol. Sci. 22, 596-601. doi: 10.1177/0956797611404083

Beck, A. T., Steer, R. A., and Brown, G. K. (1996). Manual for the Beck Depression Inventory-II. San Antonio, TX: Psychological Corporation.

Berman, M. G., Peltier, S., Nee, D. E., Kross, E., Deldin, P. J., and Jonides, J. (2011). Depression, rumination and the default network. Soc. Cogn. Affect. Neurosci. 6, 548-555. doi: 10.1093/scan/nsq080

Brown, K. W., and Ryan, R. M. (2003). The benefits of being present: mindfulness and its role in psychological well-being. J. Pers. Soc. Psychol. 84, 822-848. doi: 10.1037/0022-3514.84.4.822

Callard, F., Smallwood, J., Golchert, J., and Margulies, D. S. (2013). The era of the wandering mind? Twenty-first century research on self-generated mental activity. Front. Psychol. 4:891. doi: 10.3389/fpsyg.2013.00891

Cattell, R. B. (1966). Scree test for number of factors. Multivariate Behav. Res. 1, 245-276. doi: 10.1207/s15327906mbr0102_1

Christoff, K., Gordon, A. M., Smallwood, J., Smith, R., and Schooler, J. W. (2009). Experience sampling during fMRI reveals default network and executive system contributions to mind wandering. Proc. Natl. Acad. Sci. U.S.A. 106, 8719-8724. doi: 10.1073/pnas.0900234106

Christoff, K., Gordon, A. M., and Smith, R. (2011). "The role of spontaneous thought in human cognition," in Neuroscience of Decision Making, eds O. Vartanian and D. R. Mandel (New York, NY: Psychology Press), 259-284.

Deng, Y.-Q., Li, S., and Tang, Y.-Y. (2012). The relationship between wandering mind, depression and mindfulness. Mindfulness 1-5. doi: 10.1007/s12671-0120157-7

Diaz, B. A., Van Der Sluis, S., Moens, S., Benjamins, J. S., Migliorati, F., Stoffers, D., et al. (2013). The Amsterdam Resting-State Questionnaire reveals multiple phenotypes of resting-state cognition. Front. Hum. Neurosci. 7:446. doi: 10.3389/fnhum.2013.00446

Epel, E. S., Puternam, E., Lin, J., Blackbunr, E., Lazaro, A., and Mendes, W. B. (2013). Wandering minds and aging cells. Clin. Psychol. Sci. 1, 75-83. doi: $10.1177 / 2167702612460234$

Fenigstein, A., Scheier, M. F., and Buss, A. H. (1975). Public and private selfconsciousness-assessment and theory. J. Consult. Clin. Psychol. 43, 522-527. doi: $10.1037 /$ h0076760

Franklin, M. S., Mrazek, M. D., Anderson, C. L., Smallwood, J., Kingstone, A., and Schooler, J. W. (2013). The silver lining of a mind in the clouds: interesting musings are associated with positive mood while mind-wandering. Front. Psychol. 4:583. doi: 10.3389/fpsyg.2013.00583

Franklin, M. S., Smallwood, J., and Schooler, J. W. (2011). Catching the mind in flight: using behavioral indices to detect mindless reading in real time. Psychon. Bull. Rev. 18, 992-997. doi: 10.3758/s13423-011-0109-6

Gaab, N., Gabrieli, J. D., and Glover, G. H. (2008). Resting in peace or noise: scanner background noise suppresses default-mode network. Hum. Brain Mapp. 29, 858-867. doi: 10.1002/hbm.20578

Giambra, L. M. (1980). A factor-analysis of the items of the imaginal processes inventory. J. Clin. Psychol. 36, 383-409. doi: 10.1002/jclp.6120360203

Giambra, L. M., and Traynor, T. D. (1978). Depression and daydreaming analysis based on self-ratings. J. Clin. Psychol. 34, 14-25. doi: 10.1002/10974679(197801)34:1<14::AID-JCLP2270340103>3.0.CO;2-\#

Golding, J. M., and Singer, J. L. (1983). Patterns of inner experience-daydreaming styles, depressive moods, and sex-roles. J. Pers. Soc. Psychol. 45, 663-675. doi: 10.1037/0022-3514.45.3.663

Gorsuch, R. L. (1983). Factor Analysis. Hillsdale, NJ: Lawrence Erlbaum Associates. 
Grant, A. M., Franklin, J., and Langford, P. (2002). The self-reflection and insight scale: a new measure of private self-consciousness. Soc. Behav. Pers. 30, 821-835. doi: $10.2224 /$ sbp.2002.30.8.821

Green, G. H. (1923). The Daydream: A Study in Development. London: University of London Press.

Greicius, M. D., Flores, B. H., Menon, V., Glover, G. H., Solvason, H. B., Kenna, H., et al. (2007). Resting-state functional connectivity in major depression: abnormally increased contributions from subgenual cingulate cortex and thalamus. Biol. Psychiatry 62, 429-437. doi: 10.1016/j.biopsych.2006.09.020

Hamilton, J. P., Chen, G., Thomason, M. E., Schwartz, M. E., and Gotlib, I. H. (2011). Investigating neural primacy in major depressive disorder: multivariate Granger causality analysis of resting-state fMRI time-series data. Mol. Psychiatry 16, 763-772. doi: 10.1038/mp.2010.46

Hayes, A. F. (2009). Beyond baron and kenny: statistical mediation analysis in the new millennium. Commun. Monogr. 76, 408-420. doi: $10.1080 / 03637750903310360$

Hayes, A. F. (2013). Introduction to Mediation, Moderation, and Conditional Process Analysis: A Regression-Based Approach. New York, NY: The Guilford Press.

Hommel, B., Fischer, R., Colzato, L. S., van den Wildenberg, W. P., and Cellini, C. (2012). The effect of fMRI (noise) on cognitive control. J. Exp. Psychol. Hum. Percept. Perform. 38, 290. doi: 10.1037/a0026353

Horn, J. L. (1965). A rationale and test for the number of factors in factor-analysis. Psychometrika 30, 179-185. doi: 10.1007/BF02289447

Killingsworth, M. A., and Gilbert, D. T. (2010). A wandering mind is an unhappy mind. Science 330, 932-932. doi: 10.1126/science.1192439

Klinger, E. (1971). Structure and Functions of Fantasy. New York, NY: Wiley.

Klinger, E. (1990). Daydreaming: Using Waking Fantasy and Imagery for SelfKnowledge and Creativity. Los Angeles, CA: Tarcher.

Klinger, E. (1996). "The content of thoughts: interference as the downside of adaptive normal mechanisms in thought flow," in Cognitive Interference: Theories, Methods, and Findings, eds I. G. Sarason, G. R. Pierce, and B. R. Sarason (Mahwah, NJ: Lawrence Erlbaum Associates), 3-23.

Klinger, E. (2009). "Daydreaming and fantasizing: thought flow and motivation," in Handbook of Imagination and Mental Simulation, eds K. D. Markman, W. M. P. Klein, and J. A. Suhr (New York, NY: Psychology Press), 225-240.

Klinger, E. (2013). Goal Commitments and the content of thoughts and dreams: basic principles. Front. Psychol. 4:415. doi: 10.3389/fpsyg.2013.00415

Klinger, E., and Cox, W. M. (1987/88). Dimensions of thought flow in everyday life. Imagination Cogn. Pers. 7, 105-128. doi: 10.2190/7K24-G343-MTQW-115V

Klinger, E., Henning, V. R., and Janssen, J. M. (2009). Fantasy-proneness dimensionalized: dissociative component is related to psychopathology, daydreaming as such is not. J. Res. Pers. 43, 506-510. doi: 10.1016/j.jrp.2008.12.017

Koster, E. H. W., De Lissnyder, E., Derakshan, N., and De Raedt, R. (2011). Understanding depressive rumination from a cognitive science perspective: the impaired disengagement hypothesis. Clin. Psychol. Rev. 31, 138-145. doi: 10.1016/j.cpr.2010.08.005

Lorenzo-Seva, U., and Ferrando, P. J. (2006). FACTOR: a computer program to fit the exploratory factor analysis model. Behav. Res. Methods 38, 88-91. doi: 10.3758/BF03192753

Mar, R. A., Mason, M. F., and Litvack, A. (2012). How daydreaming relates to life satisfaction, loneliness, and social support: the importance of gender and daydream content. Conscious. Cogn. 21, 401-407. doi: 10.1016/j.concog.2011.08.001

Marchetti, I., and Koster, E. H. (2014). Brain and intersubjectivity: a Hegelian hypothesis on the self-other neurodynamics. Front. Hum. Neurosci. 8:11. doi: 10.3389/fnhum.2014.00011

Marchetti, I., Koster, E. H., Sonuga-Barke, E. J., and De Raedt, R. (2012a). The default mode network and recurrent depression: a neurobiological model of cognitive risk factors. Neuropsychol. Rev. 22, 229-251. doi: 10.1007/s11065-0129199-9

Marchetti, I., Koster, E. H. W., and De Raedt, R. (2012b). Mindwandering heightens the accessibility of negative relative to positive thought. Conscious. Cogn. 21, 1517-1525. doi: 10.1016/j.concog.2012.05.013

Marchetti, I., Koster, E. H. W., and De Raedt, R. (2013). Rest-related dynamics of risk and protective factors for depression: a behavioral study. Clin. Psychol. Sci. 1, 443-451. doi: 10.1177/2167702613489668

Martinsen, E. W. (2008). Physical activity in the prevention and treatment of anxiety and depression. Nord. J. Psychiatry 62, 25-29. doi: $10.1080 / 08039480802315640$
Mason, M. F., Norton, M. I., Van Horn, J. D., Wegner, D. M., Grafton, S. T., and Macrae, C. N. (2007). Wandering minds: the default network and stimulusindependent thought. Science 315, 393-395. doi: 10.1126/science.1131295

Mathieu, J. E., and Taylor, S. R. (2006). Clarifying conditions and decision points for mediational type inferences in organizational behavior. J. Organ. Behav. 27, 1031-1056. doi: 10.1002/job.406

McVay, J. C., and Kane, M. J. (2012). Why does working memory capacity predict variation in reading comprehension? On the influence of mind wandering and executive attention. J. Exp. Psychol. Gen. 141, 302-320. doi: 10.1037/a0025250

Meyer, T. D., Finucane, L., and Jordan, G. (2011). Is risk for mania associated with increased daydreaming as a form of mental imagery? J. Affect. Disord. 135, 380-383. doi: 10.1016/j.jad.2011.06.002

Mooneyham, B. W., and Schooler, J. W. (2013). The costs and benefits of mindwandering: a review. Can. J. Exp. Psychol. 67, 11-18. doi: 10.1037/a0031569

Mrazek, M. D., Smallwood, J., and Schooler, J. W. (2012). Mindfulness and mindwandering: finding convergence through opposing constructs. Emotion 12, 442-448. doi: 10.1037/a0026678

Nolen-Hoeksema, S., Wisco, B. E., and Lyubomirsky, S. (2008). Rethinking Rumination. Perspect. Psychol. Sci. 3, 400-424. doi: 10.1111/j.1745-6924.2008.00088.x

Northoff, G., Heinzel, A., Greck, M., Bennpohl, F., Dobrowolny, H., and Panksepp, J. (2006). Self-referential processing in our brain-a metaanalysis of imaging studies on the self. Neuroimage 31, 440-457. doi: 10.1016/j.neuroimage.2005.12.002

Preacher, K. J., and Hayes, A. F. (2008). Asymptotic and resampling strategies for assessing and comparing indirect effects in multiple mediator models. Behav. Res. Methods 40, 879-891. doi: 10.3758/BRM.40.3.879

Raes, F., Hermans, D., and Eelen, P. (2003). De Nederlandstalige versie van de Ruminative Response Scale (RRS-NL) en de Rumination on Sadness Scale (RSS-NL). Gedragstherapie 36, 97-104.

Raichle, M. E., MacLeod, A. M., Snyder, A. Z., Powers, W. J., Gusnard, D. A., and Shulman, G. L. (2001). A default mode of brain function. Proc. Natl. Acad. Sci. U.S.A. 98, 676-682. doi: 10.1073/pnas.98.2.676

Roberts, C., and Stark, P. (2008). Readiness for self-directed change in professional behaviours: factorial validation of the Self-reflection and Insight Scale. Med. Educ. 42, 1054-1063. doi: 10.1111/j.1365-2923.2008.03156.x

Rondinoni, C., Amaro, E. Jr., Cendes, F., dos Santos, A. C., and Salmon, C. E. G. (2013). Effect of scanner acoustic background noise on strict resting-state fMRI. Braz. J. Med. Biol. Res. 46, 359-367. doi: 10.1590/1414-431X20132799

Rosner, R. I., Lyddon, W. J., and Freeman, A. (eds.). (2004). Cognitive Therapy and Dreams. New York, NY: Springer.

Ruby, F. J., Smallwood, J., Engen, H., and Singer, T. (2013). How self-generated thought shapes mood-the relation between mind-wandering and mood depends on the socio-temporal content of thoughts. PLOS ONE 8:e77554. doi: 10.1371/journal.pone.0077554

Sauter, F. M., Heyne, D., Blote, A. W., van Widenfelt, B. M., and Westenberg, P. M. (2010). Assessing therapy-relevant cognitive capacities in young people: development and psychometric evaluation of the self-reflection and insight scale for youth. Behav. Cogn. Psychother. 38, 303-317. doi: 10.1017/S135246581 0000020

Schilbach, L., Bzdok, D., Timmermans, B., Fox, P. T., Laird, A. R., Vogeley, K., et al. (2012). Introspective minds: using ALE meta-analyses to study commonalities in the neural correlates of emotional processing, social \& unconstrained cognition. PLoS ONE 7:e30920. doi: 10.1371/journal.pone.0030920

Schilbach, L., Eickhoff, S. B., Rotarska-Jagiela, A., Fink, G. R., and Vogeley, K. (2008). Minds at rest? Social cognition as the default mode of cognizing and its putative relationship to the "default system" of the brain. Conscious. Cogn. 17, 457-467. doi: 10.1016/j.concog.2008.03.013

Singer, J. L., and Antrobus, J. S. (1970). Manual for the Imaginal Processes Inventory. Princeton, NJ: Education Testing Service.

Singer, J. L., and Antrobus, J. S. (1972). "Daydreaming, imaginal processes, and personality: a normative study," in The Function and Nature of Imagery, ed P. Sheehan (New York, NY: Academic Press), 175-202.

Smallwood, J. (2013). Distinguishing how from why the mind wanders: a processoccurrence framework for self-generated mental activity. Psychol. Bull. 139, 519-535. doi: 10.1037/a0030010

Smallwood, J., and Andrews-Hanna, J. (2013). Not all minds that wander are lost: the importance of a balanced perspective on the mind-wandering state. Front. Psychol. 4:441. doi: 10.3389/fpsyg.2013.00441 
Smallwood, J., Brown, K. S., Baird, B., Mrazek, M. D., Franklin, M. S., and Schooler, J. W. (2012). Insulation for daydreams: a role for tonic norepinephrine in the facilitation of internally guided thought. PLoS ONE 7:e33706. doi: 10.1371/journal.pone.0033706

Smallwood, J., Davies, J. B., Heim, D., Finnigan, F., Sudberry, M., O’Connor, R., et al. (2004). Subjective experience and the attentional lapse: task engagement and disengagement during sustained attention. Conscious. Cogn. 13, 657-690. doi: 10.1016/j.concog.2004.06.003

Smallwood, J., O'Connor, R. C., and Heim, D. (2004/05). Rumination, dysphoria, and subjective experience. Imagination Cogn. Pers. 24, 355-367. doi: 10.2190/AE18-AD1V-YF7L-EKBX

Smallwood, J., O'Connor, R. C., Sudbery, M. V., and Obonsawin, M. (2007). Mind-wandering and dysphoria. Cogn. Emot. 21, 816-842. doi: 10.1080/02699930600911531

Smallwood, J., Ruby, F. J., and Singer, T. (2013). Letting go of the present: mindwandering is associated with reduced delay discounting. Conscious. Cogn. 22, 1-7. doi: 10.1016/j.concog.2012.10.007

Smallwood, J., and Schooler, J. W. (2006). The restless mind. Psychol. Bull. 132, 946-958. doi: 10.1037/0033-2909.132.6.946

Smallwood, J., Schooler, J. W., Turk, D. J., Cunningham, S. J., Burns, P., and Macrae, C. N. (2011). Self-reflection and the temporal focus of the wandering mind. Conscious. Cogn. 20, 1120-1126. doi: 10.1016/j.concog.2010.12.017

Smilek, D., Carriere, J. S., and Cheyne, J. A. (2010). Out of mind, out of sight eye blinking as indicator and embodiment of mind wandering. Psychol. Sci. 21, 786-789. doi: 10.1177/0956797610368063

Sobel, M. E. (1982). "Asymptotic confidence intervals for indirect effects in structural equation models," in Sociological Methodology 1982, ed S. Leinhardt (Washington, DC: American Sociological Association), 290-312.

Stawarczyk, D., Majerus, S., Maquet, P., and D’Argembeau, A. (2011). Neural correlates of ongoing conscious experience: both task-unrelatedness and stimulusindependence are related to default network activity. PLOS ONE 6:e16997. doi: 10.1371/journal.pone.0016997

Stawarczyk, D., Majerus, S., Van der Linden, M., and D’Argembeau, A. (2012). Using the daydreaming frequency scale to investigate the relationships between mind-wandering, psychological well-being, and present-moment awareness. Front. Psychol. 3:363. doi: 10.3389/fpsyg.2012.00363
Stevens, J. P. (2002). Applied Multivariate Statistics for the Social Sciences, 4th Edn. Hillsdale, NJ: Erlbaum.

Treynor, W., Gonzalez, R., and Nolen-Hoeksema, S. (2003). Rumination reconsidered: a psychometric analysis. Cognit. Ther. Res. 27, 247-259. doi: 10.1023/A:1023910315561

Van der Does, W. (2002). De Nederlandse versie van de Beck Depression InventoryTweede Editie. Lisse: Swets and Zeitlinger.

Velicer, W. F. (1976). Determining number of components from matrix of partial correlations. Psychometrika 41, 321-327. doi: 10.1007/BF02293557

Whitfield-Gabrieli, S., and Ford, J. M. (2012). Default mode network activity and connectivity in psychopathology. Annu. Rev. Clin. Psychol. 8, 49-76. doi: 10.1146/annurev-clinpsy-032511-143049

Zhu, X. L., Wang, X., Xiao, J., Liao, J., Zhong, M. T., Wang, W., et al. (2012). Evidence of a dissociation pattern in resting-state default mode network connectivity in first-episode, treatment-naive major depression patients. Biol. Psychiatry 71, 611-617. doi: 10.1016/j.biopsych.2011.10.035

Zwick, W. R., and Velicer, W. F. (1986). Comparison of 5 rules for determining the number of components to retain. Psychol. Bull. 99, 432-442. doi: 10.1037/00332909.99.3.432

Conflict of Interest Statement: The authors declare that the research was conducted in the absence of any commercial or financial relationships that could be construed as a potential conflict of interest.

Received: 14 October 2013; accepted: 21 February 2014; published online: 18 March 2014.

Citation: Marchetti I, Van de Putte E and Koster EHW (2014) Self-generated thoughts and depression: from daydreaming to depressive symptoms. Front. Hum. Neurosci. 8:131. doi: 10.3389/fnhum.2014.00131

This article was submitted to the journal Frontiers in Human Neuroscience.

Copyright (c) 2014 Marchetti, Van de Putte and Koster. This is an open-access article distributed under the terms of the Creative Commons Attribution License (CC BY). The use, distribution or reproduction in other forums is permitted, provided the original author(s) or licensor are credited and that the original publication in this journal is cited, in accordance with accepted academic practice. No use, distribution or reproduction is permitted which does not comply with these terms. 